\title{
Feasibility analysis of experiential training in BiGuiYuan School Guangdong Province
}

\author{
Chen $\mathrm{Ge}^{1 \mathrm{a}}$, Wang Jun ${ }^{1 \mathrm{~b} *}$ \\ ${ }^{1}$ College of physical education, Yunnan Agricultural University, Kunming, China \\ Aemail:839995160@qq.com, bemail:158291721@qq.com \\ * Corresponding Author
} Keywords: Guangdong Country Province BiGuiYuan School; experiential training; school
classroom

\begin{abstract}
In recent years, experiential training has been carried out in a prosperous way, gradually transitioning from adult training to adolescents. Especially the summer camps and winter camps for the holidays have been popular among parents and children. Then the experiential training entered the classroom of students has gradually become a trend. Guangdong Province BiGuiYuan School is also introducing this kind of learning style, taking students as the main body, doing middle school, learning first, cultivating students' willing character and way of thinking, strengthening communication and cooperation among students, and enhancing team cohesion.
\end{abstract}

\section{体验式训练进广东碧桂园学校课堂可行性分析}

\author{
陈歌 $1 \mathrm{a}$, 王钧 $1 \mathrm{~b}$ * \\ 1 云南农业大学体育学院, 昆明, 中国 \\ Aemail: 839995160@qq.com, cemail: 158291721@qq.com \\ *通讯作者
}

关键词: 广东碧桂园学校; 体验式培训; 学校课堂

摘要: 近年来, 体验式培训做得是风生水起, 逐渐从成人培训过渡到青少年。特别是假期的 夏令营和冬令营, 受到了家长和孩子们的热捧。那么体验式培训进入学生的课堂也逐渐成了 一种趋势。广东碧桂园学校也在引进这种学习方式, 以学生为主体, 在做中学, 先行后知, 培养学生的意志品格和思维方式, 加强学生间的沟通与合作, 增强团队凝聚力。

\section{1. 引言}

拓展训练，又称体验式培训。起源于英国海军的军事拓展训练，当时经过训练的海军部 队在身体素质和心理抗压能力上都有了很大提升, 当战争来临时, 能经受住战争的考验。到 了和平年代, 许多管理学和行为学专家对其进行进一步研究, 将体验式培训逐渐发展成为专 门的课程, 并将其中的一些项目应用于企业培训中, 在一定程度上提升了企业绩效, 强化了 管理。

早在 1995 年体验式培训从国外引进大陆, 在企业管理中发挥了极大的作用, 特别是在 加强团队的凝聚力, 员工的执行力方面。但其主要集中在成人培训中, 包括不少高校也在逐 
渐推行这类型的培训, 它有利于促进学校体育课程改革, 加强学生的思想政治教育, 提升学 生综合素质，给予学生就业指导方向，增加社会适应性和提高学生的心理健康水平。

体验式培训进入学校, 并进入学生的课堂, 这在国内还是新鲜事。但碧桂园集团有教育 情怀, 拥有合理的管理和运营模式支持。广东碧桂园学校重视学生的素质教育, 特别是学生 的领导力, 包括做决定、计划技巧、问题解决、个人特质、价值澄清、尊重关怀、口语沟 通、书写沟通和团队动力九大领导力, 这是常规课程给不了学生的, 但是体验式培训能将这 些领导力的方式, 通过课程的形式带给学生们。以体验式培训开展的方式将素质拓展, 融入 到学校的课堂中去, 让学生能在校园内接受到培训, 这也为体验式培训进入课堂提供了可 能。

\section{2. 体验式培训在广东碧桂园学校开展现状}

\section{1 体验式培训进入学校}

1992 年, 广东碧桂园学校成立, 与北京景山学校合作, 引进先进的管理模式, 借助名 校的名牌和雄厚的师资力量, 打响了教育带动地产的第一枪。1994 年至 2010 年, 学校树 立起了两座丰碑：一是成功构建了 “十二字” 教育模式：保证基础，发展个性，服务社会; 二是成功引进了 IB 全人教育课程。2011 年, 学校创办者要求广东碧桂园学校进行 “二次创 业” , 首次提出了 “要把广东碧桂园学校办成教育行业中的 “奢侈品” ”, 要继续深化教育 模式的探索和实践, 促进学校内涵发展, 提升学校办学品位, 建成中国名校和世界名校 ${ }^{[1]}$ 。

2012 年至 2017 年, 广东碧桂园学校开始引入体验式培训, 在每年 9 月初, 开始对高中 部的学生进行为期 5 天的体验式培训。期间会给学生安排趣味运动会和一些拓展项目, 第 一: 为了让学生收心, 经过近 2 个月的暑假, 大家都有着不同的经历, 经过一次活动, 让大 家把心思投入到学习中来; 第二: 加强集体荣誉感, 整个拓展活动, 是以班级为单位, 班级 成员在活动中通过团结协作和相互沟通, 增进彼此了解, 相互信任, 从而熔炼团队; 第三: 激发自我的潜力, 在拓展活动中, 每个环节都需要自己全身心的投入, 在不断投入过程中, 也一次次挑战自我, 超越自我。短期大强度的培训, 能让学生有一定的感悟, 但体验式培训 中没有对与错, 能收获多少, 主要在于个人投入多少。

\section{2 传统课堂没有对领导力的要求}

中国式教育以文化知识教授为核心，大多数父母都想自己的孩子多读点书，接受更多的 教育, 对于语、数、英、政、史、地、物、化、生等这些传统的学科来说, 花心思、花时间 在这些学科上面是很重要的, 这是升学的关键, 考上好大学, 找个好工作, 当公务员或者教 师, 都是不错的职业, 也是很多父母对子女的愿望。领导力这个词, 许多家长是没有考虑到 的, 觉得孩子读的书多了, 了解的知识多了, 自然就会拥有领导力了。其实不然, 领导力是 需要培养, 不断学习, 不断经历。广东碧桂园学校致力于学生全面发展, 课堂上安排许多精 品课程, 课外也有丰富多彩的社团活动, 但对于领导力的要求几乎没有, 因为这很难实现, 也没有明确的概念来支撑。

\section{3 课外活动丰富}

广东碧桂园学校注重学生的全面发展, 每年学校会组织研学活动, 前往国内外的风景区 和知名大学进行研学活动。学校注重学生的素质教育, 鼓励学生个性化发展, 开展多类课程 供学生选择。每年假期, 学校还组织高年级的学生前往贫困山区进行支教活动, 让学生感受 乡村生活, 体验不一样的生活环境, 目的是让孩子时常抱有一个感恩之心, 做一个对社会有 价值的人。 


\section{3. 体验式培训在广东碧桂园学校开展影响因素}

\section{1 教育理念}

广东碧桂园学校培养的是拥有 “国际思维, 中国灵魂” 的学生, 这是学校的教育理念, 学校的领导者对于教育理念的贯彻至关重要。学校培养的是国际化人才, 因此领导者能接受 新鲜的事物, 特别是这些先进的教育思想。学校也在不断的探索新的教学模式, 引进国外先 进的教学理念和思想, 然后将其本土化。教育理念的传递, 是信念植入的过程, 要想学生能 快速成长, 需要的是教育工作者将学校的信念传递给学生, 将学生的知识库填入新的东西。

\section{2 师生有需求}

大部分学校的目标是：学生在毕业后能适应社会，能被社会所接纳。而广东碧桂园学校 培养学生的目标不一样, 他们想集中力量将学生培养为社会的精英, 社会的引领者。作为一 个民办学校, 作为一个贵族学校, 这是学校的使命, 同时也是家长对学校的期待, 家长希望 自己的孩子能赢在人生的起跑线上，愿意在孩子身上投入大量的时间和金钱。学生也更希望 能多接受一些新鲜的课程, 因为孩子的天性就是喜欢玩, 既能学习新知识, 又能开心玩要, 学生还是很愿意接受的。

领导力在一定程度上其实也就是影响力, 能影响多少人, 取决于我们的能力, 这需要的 是综合素质, 要想突破重围, 就得让学生具备一定的领导力。因此, 学校也为了学生的进一 步提升, 将体验式培训引入课堂。将领导力提升的课程分为九个子课程, 夯实好每一门课程, 让学生亲自去体验, 在体验中得到成长。

\section{3 师资队伍}

一门课程的安排, 师资队伍肯定少不了的, 基于前几年广东碧桂园学校和校外的拓展培 训机构合作, 开展了6年的短期拓展培训, 培训机构的能力肯定是具备的, 选择合适的机构 合作就行。但是体验式培训进入校园, 真正给学生上课, 并且会针对 1 至 12 年级的学生, 年 级层次跨度很大, 还存在少部分外国学生, 不仅需要培训师具备拓展训练经验以外, 还需要 培训师了解学校教育学的知识, 对学生培训有一定的经验。

\section{4 课程安排}

体验式培训进入校园, 肯定会带有目标的, 而广东碧桂园学校的目标是, 想通过体验式培训来 提升学生的九大领导力。课程安排横跨小学部、初中部和高中部, 包括中国课和国际课。在校的 12 个年级, 160 个班级, 每个班级 26 名学生, 每次 2 个班级 52 名学生一起开课。九大领导能力融入到每 个阶段中去, 每个阶段不断对其进行强化, 课程的内容在每个阶段安排也是不一样的, 由易到难, 由低空到高空, 由小组到团队大融合。

不同的阶段需要面对学生的情况也是不同的。小学阶段: 学生身心逐渐发育, 容易出现以自我 为中心, 需要正确的引导; 初中阶段: 学生身体迅速发育, 开始出现逆反心理; 高中阶段: 身体各 器官逐渐成熟, 心理特征表现是复杂的。渴望得到关注, 又希望有自己的独立空间。学校每年会提 供一定名额的出省, 甚至出国交流学习的机会, 学校会把各种资源对接好, 但是外出的费用需要学 生自费, 由老师带领一起出去交流学习。除了常规的体验式课程安排外, 还有下面的一些 特色课程补充。 
图2 体验式课程安排表

\begin{tabular}{|c|c|c|c|c|c|}
\hline $\begin{array}{l}\text { 营 } \\
\text { 地 } \\
\text { 教 } \\
\text { 育 }\end{array}$ & $\begin{array}{l}\text { 军旅少年行、军事体 } \\
\text { 验训练营 }\end{array}$ & $\begin{array}{l}\text { 中国少年骑兵营、骑 } \\
\text { 马射箭滑伞 }\end{array}$ & $\begin{array}{l}\text { 自然探索成长营、森 } \\
\text { 林知识自然探究户 } \\
\text { 外技巧 }\end{array}$ & \multicolumn{2}{|c|}{ 乡村野趣营、体验农耕文化 } \\
\hline $\begin{array}{l}\text { 主 } \\
\text { 题 } \\
\text { 课 } \\
\text { 程 }\end{array}$ & $\begin{array}{l}\text { 大草原深度穿越+沙 } \\
\text { 漠徒步毅行 } 70 \mathrm{KM} \text { 徒 } \\
\text { 步穿越+骑行 }\end{array}$ & $\begin{array}{l}\text { 沙漠徒步毅行沙漠 } \\
\text { 越野+徒步+拍电影 }\end{array}$ & $\begin{array}{l}\text { 荒野行动体验营、原 } \\
\text { 始森林、探险体验 }\end{array}$ & $\begin{array}{l}\text { 高尔夫球、 } \\
\text { 主题课高端 } \\
\text { 户外体验 }\end{array}$ & $\begin{array}{c}\text { 棒球、体验课 } \\
\text { 程、竞技与智 } \\
\text { 慧的结合 }\end{array}$ \\
\hline $\begin{array}{l}\text { 研 } \\
\text { 学 }\end{array}$ & $\begin{array}{c}\text { 家风建设、了解家 } \\
\text { 风+践行家风 }\end{array}$ & $\begin{array}{l}\text { 文化传承、弘扬中 } \\
\text { 华民族、传统文化 }\end{array}$ & $\begin{array}{c}\text { 历史探寻、了解过 } \\
\text { 去+认识现在+把握 } \\
\text { 未来 }\end{array}$ & \multicolumn{2}{|c|}{ 名人故居、文化熏陶+游学 } \\
\hline
\end{tabular}

\section{5 资金来源}

2018 学年入读中国高中课程的新生, 100\%享受优惠, 优惠后学杂费如下: 普通高考生: 4.8 万元/学年; 港澳台侨外籍生: 4.8 万元/学年; 艺术高考生: 5.3 万元/学年。 ${ }^{[2]}$ 从学校的 收费标准来看, 这是学校的一笔可观收入。为学校各项活动的开展提供了强大的物质保障。 现如今广东碧桂园学校是由企业独立进行运营, 只对学校进行运营管理, 专人负责专职, 师 生配备标准是 1: 6 , 平均 1 个老师对接 6 个学生, 这种导师制的师资投入, 一般只出现在我 国硕士研究生教育阶段。学校愿意花大量人力和财力付出, 将学生培养成精英, 将学生送入 更高的平台时, 学校的口碑也打造出来了。品牌的力量是强大的, 况且孩子的教育没有回头 路，走的每一步都算数，因此，家长更愿意让孩子去广东碧桂园学校就读。

\section{6 器材设备}

广东碧桂园学校有一个400米的标准塑胶田径场和一个200米塑胶运动场，还有一个 $2400 \mathrm{~m}^{2}$ 的室内综合体育馆，室外标准泳池和室内泳池多类运动场馆等。

2017年底, 广东碧桂园学校开始为体验式培训开展采购各种器材设备, 预计2018年9月 份开始投入使用。低空绳索挑战项目设施, 包括甜甜圈、隔岛跃进、黑羊白羊等; 高空绳索 挑战项目设备, 包括天空之岛、巨人梯、节节高升等; 攀岩墙项目器械, 包括攀岩墙一套 等。学校还规划出大片的区域, 用于保障体验式培训的顺利开展。

\section{7 安全事项}

无论校园开展任何活动, 安全是把利剑, 时刻需要注意。培训师是每次课程的负责人, 在每次课程开始之前一定要对活动的器材进行检查。特别是高空绳索设施, 课堂中要注意对 安全事项的强调, 提醒学生时刻注意自身安全。在活动开始前, 做好安全调查, 看有没有身 体不适的学生, 让其私下和培训师沟通, 以免出现安全事故。

在活动进行过程中, 关注学生在活动中的表现, 鼓励学生挑战自我的同时, 注意学生反 馈的信息，一切以安全为前提，做好安全预案。

一旦出现安全事故, 首先要做的是:第一, 停止学生的一切活动, 将学生立即转移到安 全的地方; 第二, 让班长或其它班干部过来协助处理受伤的学生, 旁边的培训师先组织班级 的其与学生去别处活动; 第三, 培训师和班长或其它班干部一起送学生到学校医务室, 进一 步了解伤情, 若无大碍, 由班干部协助处理即可, 若伤情严重, 马上打电话通知班主任, 让 班主任再通知其家长; 第四, 若情节很严重, 需要进一步检查, 则让医务室打电话给 120 , 培训师也需要陪伴前往医院了解进一步伤情, 直到班主任或家长到来, 交接好后, 方可离 开。 


\section{4. 建议}

\section{1 关于培训师}

广东碧桂园学校国际部存在一部分外国学生, 有来自日本、澳洲和韩国等地区。为了培 训能更好的进行, 第一: 对培训师的要求更高, 需要培训师具备一定的英语口语沟通能力; 第二: 培训师角色需要转变, 体验式培训进入校园, 与校外的社会拓展不一样, 学校对学生 时间要求严格, 要按照学校的课程安排来进行。

\section{2 做好应急预案}

体验式培训很多活动都是在户外开展的, 特别是一些高空绳索项目, 危险性很大。除了 培训师特别强调外, 第一: 需要给参加活动的学生购买当天活动保险; 第二: 向学校医务室 备案, 提前熟悉学校附近的三甲医院, 防止突发状况发生; 第三: 课前做好危急状况演习, 防止突发状况到来不知所措。户外体验式培训比一般的体育教学危险性更高, 课程之前更应 该让学生知道如何保护自己，做好危机预演，一旦发生意外事故，也能从容应对。

\section{3 建立反馈机制}

体验式培训进入校园的参考资料较少, 学生能有多少收获, 学生的反馈如何? 这些都需 要在培训中不断跟进。建立一个良好的反馈系统, 将学生一培训师一班主任三者联系起来, 让培训融入到学生的学习中, 使培训不仅仅是孤立的, 它更像是课堂的延伸, 是为教学, 为 提升学生的综合素质服务的。培训师在这个反馈系统中作为一个桥梁, 连接着学生和班主 任, 根据学生的表现和班主任所看到的现象, 来调节课程的安排, 针对性的给予学生指导。

\section{4 整理相关资料}

一门新的课程进入课堂, 相关的资料整理很关键, 培训有没有收获不是哪一个学生说得 算, 也不是老师能决定的。那么, 这就得通过一些数据来呈现, 这些数据从何而来? 这就需 要培训师和班主任互相配合, 培训前进行问卷调查。第一: 将学生培训前与培训后进行对 比, 看学习成绩是否有提升; 第二: 学生的体能和综合素质是否有变化; 第三: 看班级氛围 是否有变化, 团队凝聚力是否有加强。将一些数据量化, 这就需要前期做大量的准备工作, 用数据来说话, 给学生, 给家长, 给学校一个满意的答卷。

\section{5. 结语}

体验式培训进入课堂, 是摸着石头过河, 但前途一定是光明的。广东碧桂园学校属于民 办学校, 只需要对学生和家长负责, 同时也有资金支持各项活动的开展, 这是它的优势。

体验式培训在广东碧桂园学校开展是必然: 第一, 体验式培训已经进入广东碧桂园学校 几年了, 每年都会有短期的培训, 这足以说明它是有很大的鬼米力; 第二, 学校已经规划出体 验式培训区域, 并采购许多高空设施, 大都已建成, 可投入使用; 第三, 学校的定位以及领 导者, 对新的教学思想接受程度都是开放性的。但是体验式培训在中小学的开展, 还一直没 有突破口, 我相信在广东碧桂园学校, 能开启体验式培训进入民办中小学的新篇章。

\section{致谢}

本文为云南农业大学2017年教育教学改革研究项目（2017YAUJY122）阶段性成果之一。

\section{References:}

[1] Li Chunlei. Providing the most suitable education for each student--Research and practice of "individualized education" in Guang dong Province BiGuiYuan School [J]. Educator, 2016(1): 16-17. 
[2] Guangdong Province BiGuiYuan Country Garden School official website: http://bgy.gd.cn/ 